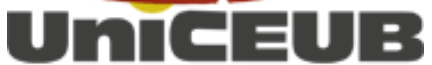 \\ Centro Unıversıtárıo de Brasílıa \\ CENTRO UNIVERSITÁRIO DE BRASÍLIA - UniCEUB \\ FACULDADE DE CIÊNCIAS DA EDUCAÇÃO E DA SAÚDE - FACES \\ PROGRAMA DE INICIAÇÃO CIENTÍFICA - PIC
}

\author{
NATHALIA OLIVEIRA BELCHIOR SILVA \\ RIAN FUJITA GASTON
}

ESTUDO DO POLIMORFISMO DA ENZIMA CONVERSORA DE ANGIOTENSINA EM CASOS DE HIPERTENSÃO 


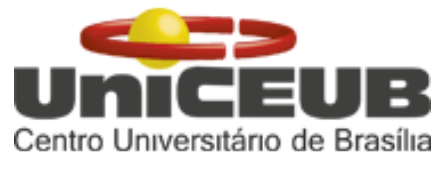

\section{NATHALIA OLIVEIRA BELCHIOR SILVA RIAN FUJITA GASTON}

\section{ESTUDO DO POLIMORFIMOS DA ENZIMA CONVERSORA DE ANGIOTENSINA EM CASOS DE HIPERTENSÃO}

Relatório final de pesquisa de Iniciação Científica apresentado à Assessoria de Pós-Graduação e Pesquisa pela Faculdade de Ciências da Educação e da Saúde - FACES.

Orientação: Paulo Roberto Queiroz.

\section{BRASÍLIA-DF}




\title{
Estudo do polimorfismo da enzima conversora de angiotensina em casos de
}

\author{
hipertensão.
}

\author{
Nathalia Oliveira Belchior Silva - UniCEUB, PIC voluntário \\ nath.o.b.s@gmail.com
}

Rian Fujita Gaston - UniCEUB, PIC voluntário

fujita.ri.g@gmail.com

Paulo Roberto Martins Queiroz - UniCEUB, professor orientador pqsilva@uol.com.br

A hipertensão se tornou um dos males que é cada vez mais associado a hábitos ambientais inadequados como dietas ricas em sal, excesso no consumo de bebidas alcoólicas e o desenvolvimento de uma rotina sedentária. Porém, é necessário ser considerado, durante o diagnóstico do paciente, fatores genéticos que contribuam para o desenvolvimento dessa condição clínica multifatorial. $O$ objetivo deste trabalho foi determinar o polimorfismo da enzima conversora de angiotensina e relacionar com hábitos ambientais, análises biológicas e possíveis casos de hipertensão. Aos voluntários foram realizadas coletas de amostras de sangue para a extração do DNA genômico de leucócitos, análise hematológica e bioquímica, além da aplicação de um questionário com o objetivo de avaliar sua qualidade de vida. A dosagem bioquímica e hematológica dos 20 participantes da pesquisa revelou que estes estavam dentro dos valores de referência. A análise por PCR-RFLP do gene ECA revelou o mesmo padrão de digestão para todos os indivíduos analisados. Mesmo com todos os resultados obtidos tendo sido normais, foi possível avaliar com base nos dados aferidos no questionário que dentre os hábitos ambientais avaliados havia uma abundância de práticas consideradas de risco pois poderiam influenciar no aumento da pressão arterial, além da informação da incidência de casos de hipertensão recorrente na família em uma quantidade majoritária do grupo de estudados. Ainda que o resultado negativo de um fator que interfere na homeostasia vascular tenha sido encontrado, é importante que seja adotado, na triagem clínica, a execução de testes moleculares para busca de outras características que podem contribuir para o surgimento da hipertensão.

Palavras-chave: Sistema renina-angiotensina, fatores de risco, cardiopatia. 


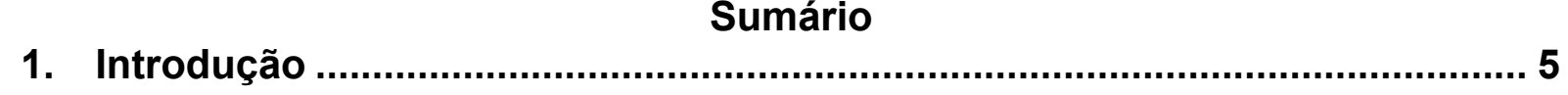

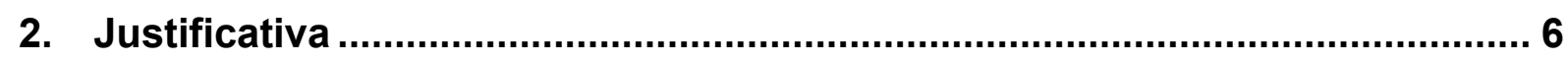

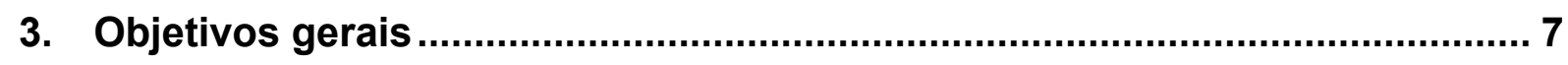

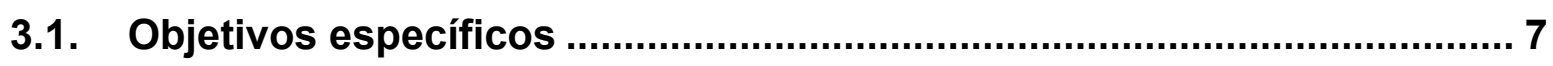

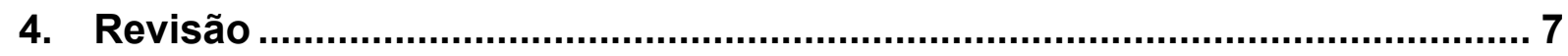

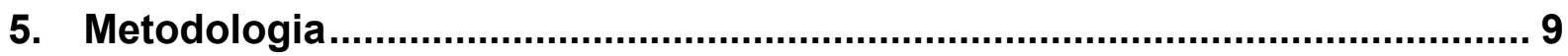

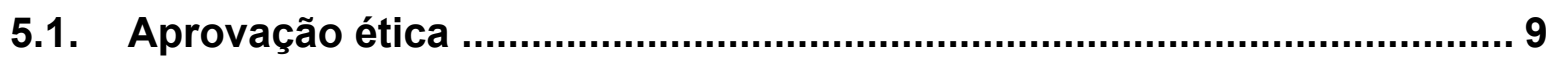

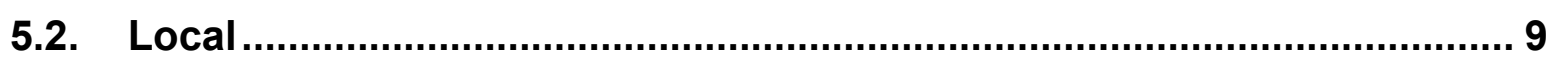

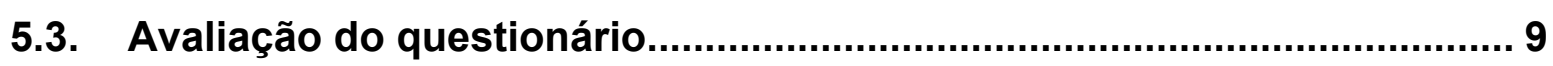

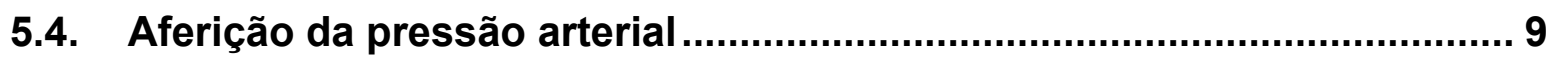

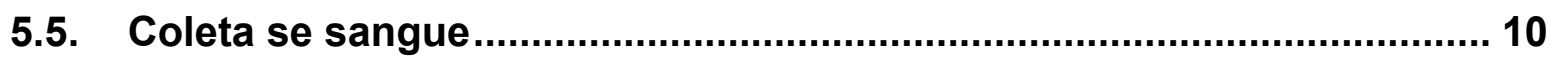

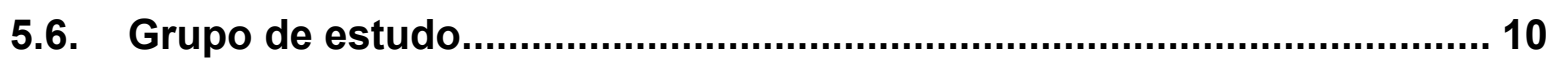

5.7. Procedimento para extração de DNA genômico dos leucócitos............ 10

5.8. Diagnóstico da mutação da ECA ....................................................... 11

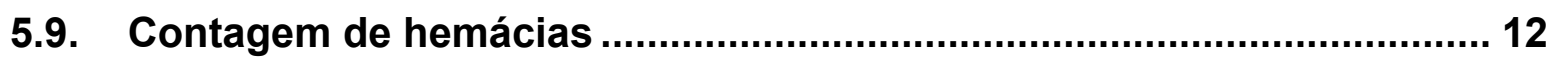

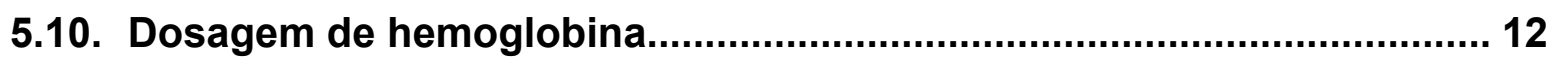

5.11. Contagem diferencial dos leucócitos................................................... 12

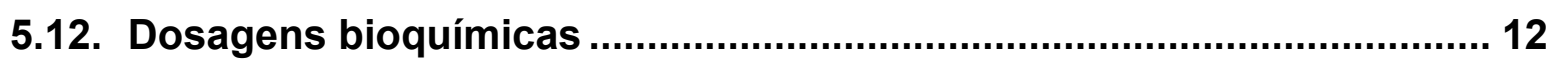

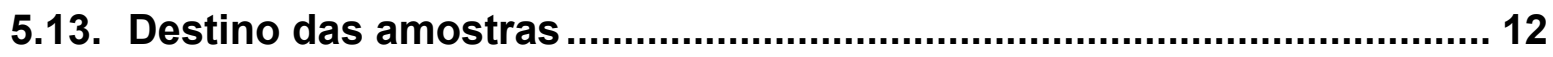

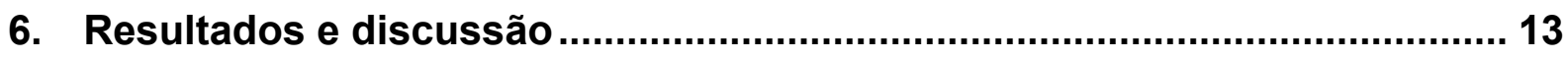

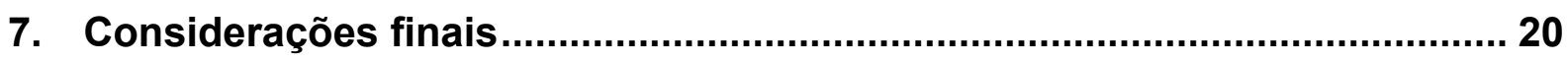

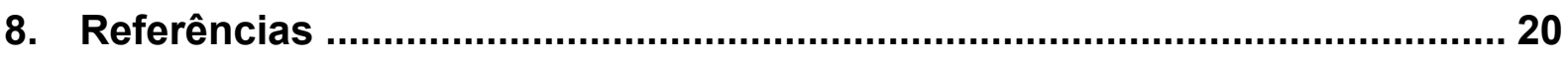

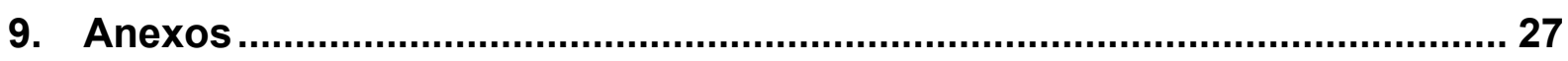

9.1 Anexo A- Autorização do Comitê de Ética.............................................. 27

9.2 Anexo B- Anuência Laboceian.......................................................... 31

9.3 Anexo C- Termo de Consentimento Livre e Declarado .......................... 33

9.4. Anexo D- Questionário para análise da qualidade de vida ................... 36 


\section{Introdução}

O eixo renina-angiotensina-aldosterona está relacionado a diversos processos fisiológicos do organismo como no controle da pressão arterial e na homeostase hidroeletrolítica. Possui capacidade de se adaptar ou influenciar processos patológicos relacionados não só ao sistema cardiovascular e renal, mas também ao início do diabetes mellitus, por exemplo. Novos elementos ainda estão sendo descobertos, mas o estudo dos componentes clássicos e o avanço de novas metodologias moleculares tem favorecido a compreensão da abrangência de seus efeitos (SANJULIANE et al., 2011).

Inicialmente a renina é liberada pelas células justaglomerulares e, ao entrar na corrente sanguínea converte o angiotensinogênio em angiotensina I. Este peptídeo é inativo e necessita ser clivado para exercer sua função no organismo. Esse processo é realizado pela enzima conversora de angiotensina (ECA), que converte a angiotensina I em angiotensina II (JÚNIOR; ABRAMOV, 2011).

A ECA também participa do sistema calicreina-cinina, promovendo a inativação da bradicinina, um agente vasodilatador (BUENO et al., 2013). Em ambos os sistemas a enzima retira dois aminoácidos dos peptídeos, promovendo a ativação de um vasoconstritor e inativando um vasodilatador (NOGUEIRA, 2011). Esse processo torna a enzima duplamente importante no controle da integridade vascular e garante a contração dos vasos incitada pelo primeiro eixo (UFF, 2016).

Presente no endotélio e plasma sanguíneo, a enzima conversora de angiotensina é uma megaloprotease de zinco produzida através da quebra de uma carboxipepitidase entre as proteinas arg663 e ser664 (BUENO et al., 2013). Está localizada no braço longo do cromossomo 17 , região 2 , banda 3 , sub-banda 3 e possui 26 exóns ( $\mathrm{NH}, 2016)$.

A quantidade de enzima no organismo é determinada por um fenômeno genético que acontece no íntron 16 do gene. A presença do polimorfismo de inserção (I) ou deleção (D) de um fragmento $A l u$, com cerca de $287 \mathrm{pb}$, provoca a presença de três genótipos distintos na população. Indivíduos homozigotos II possuem uma menor disponibilidade da enzima, indivíduos homozigotos DD possuem maior quantidade de enzima e indivíduos heterozigotos I/D possuem quantidade intermediária (COSTA 
et al., 2009). Essa característica torna possível associação da hiperatividade da ECA com a gênese de diversas doenças cardiovasculares (SANJULIANI et al., 2011).

A angiotensina II está relacionada com a atividade simpática e estimula a atividade noradrenergica periférica, promove vasoconstrição, síntese e secreção de aldosterona e liberação de ACTH e vasopressina. Estudos também indicam seu envolvimento como ativador de cascatas oxidativas e inflamatórias ocasionadas por lesões endoteliais. Portanto um aumento em sua concentração tem impacto em diversos processos fisiológicos relacionados com a modulação da pressão arterial (SAMPAIO; PINHEIRO; SANTOS, 2008).

A hipertensão é uma doença multifatorial que possui como característica a presença de níveis elevados e contínuos da pressão arterial (VI Diretrizes Brasileiras de Hipertensão, 2010). De acordo com a Sociedade Brasileira de Hipertensão, indivíduos normais possuem pressão arterial abaixo de 120/80 mmHg. Entretanto, $30 \%$ da população adulta mundial está acima desse valor $(140 / 90 \mathrm{mmHg})$, e um terço deles desconhece sua condição (PAOH, 2016).

É considerada um importante fator de risco para doenças cardiovasculares e cerebrovasculares, sendo muitas vezes relacionada com alterações estruturais e/ou funcionais de órgãos como coração e rins além de alterações metabólicas (RADOVANOVIC et al., 2014; VI DIRETRIZES BRASILEIRAS DE HIPERTENSÃO, 2010). Das 17 milhões de pessoas que morrem de doenças cardíacas todo ano, a hipertensão é responsável por 45\% (WHO, 2013).

Ainda que fatores externos como obesidade e tabagismo influenciam na origem dessa patologia, é imprescindível que durante o diagnóstico e tratamento do paciente, fatores genéticos também sejam considerados (GAMA, MUSSI; GUIMARÃES, 2010).

\section{Justificativa}

A presente pesquisa buscou aprimorar a atuação dos estudantes do curso de biomedicina ao estudar, no caso, a influência do polimorfismo da enzima conversora de angiotensina em sujeitos hipertensos e normatensos, visando ampliar os conhecimentos da relação dessa enzima com o agravo, oferecer novas estratégias 
para identificação de doentes, auxiliar na pesquisa de medicamentos e estudos posteriores, podendo associa-los com casos de hereditariedade.

\section{Objetivos gerais}

Fazer o levantamento da frequência dos genes da enzima conversora de angiotensina em indivíduos de uma comunidade acadêmica, assim como, relacionar fatores clínicos e de qualidade de vida com o polimorfismo da ECA.

\subsection{Objetivos específicos}

- Fazer análise bioquímica e hematológica das amostras dos participantes.

- Determinar a frequência genética do polimorfismo da ECA.

- Relacionar os resultados obtidos com o questionário de qualidade de vida dos participantes d apesquisa.

\section{Revisão}

O estudo feito por Freitas et al. (2007) com 82 indivíduos hipertensos residentes na região norte do Brasil constatou que o genótipo DD da ECA está associado a um aumento considerável na pressão sanguínea - cerca de $7,8 \mathrm{mmHg}$ a mais. A quantidade de enzima sérica encontrada em portadores do genótipo de deleção era quase o dobro em comparação com portadores do genótipo de inserção. Através desses achados ele afirma que a presença dessa característica no gene da enzima é um fator de risco para do desenvolvimento de hipertensão.

Ramachandran et al. (2008) identificou em pacientes malaios uma significativa presença do alelo $D$ em hipertensos quando comparado com pacientes saudáveis. Dos 65 pacientes hipertensos 36,92\% possuíam essa característica, enquanto do total de 70 indivíduos controles apenas $22,86 \%$ foram identificados com o esse alelo.

Contudo a literatura sobre o assunto ainda é conflitante. Freitas et al. (2008) afirma que isso acontece, pois, alguns estudos utilizam um grupo amostral pequeno e para Houcher et al. (2013) não é possível obter uma confirmação dessa relação visto que características como a etnia dos pesquisados também deve ser considerada. A prevalência do alelo D encontrada em sua pesquisa com 146 
argelinos foi de 70,5\%, assim como, populações árabes, enquanto na população europeia essa frequência é menor.

Outra variável que também deve ser considerada é a idade. Almeida et al. (2010) verificaram que dos 180 indivíduos com idade média de $78 \pm 8$ anos e hipertensos $86,9 \%$ possuíam o genótipo II. Analisando os dados do pesquisador, verificou-se que a frequência do alelo $D$ é homogenia entre os grupos de normotensos e hipertensos.

Inibidores da enzima conversora de angiotensina (IECA) são uma das alternativas utilizadas para impedir a progressão desse agravo. Kohlmann Junior et al. (2010) explicam que esses medicamentos bloqueiam a clivagem da angiotensina I em angiotensina II, tanto no sangue quanto nos tecidos e Ribeiro (2002) afirma que esses medicamentos são tão efetivos como outros anti-hipertensivos. Esse autor, porém, ressalva que pacientes negros reagem menos aos efeitos dos IECAS dos que pacientes brancos.

Vark et al. (2012) confirmou que em usuários de tomavam bloqueadores do receptor AT1 da Angiotensina II o valor da mortalidade se manteve estável, enquanto que houve redução $10 \%$ dos óbitos de pacientes com hipertensão que utilizaram bloqueadores da ECA. A autora conclui que, sendo a hipertensão uma das doenças com maior prevalência no mundo, o uso desse tipo de medicamento deve ser difundido.

Lima et al. (2007) revelaram que o polimorfismo inserção/deleção da ECA foi caracterizado em 1990 e corresponde a inserção (I) ou deleção (D) de 287 pares de base no íntron 16 do gene ACE. Estudos sugerem que esse polimorfismo influencia a concentração sérica de ECA; indivíduos com genótipo DD teriam as maiores concentrações séricas da ECA, enquanto aqueles com genótipo II teriam as menores. Estima-se que o alelo $D$ contribuiria com aproximadamente metade da variação dos níveis plasmáticos da ECA. 


\section{Metodologia}

\subsection{Aprovação ética}

Inicialmente, o projeto foi submetido ao Comitê de Ética em Pesquisa (CEP) do Centro Universitário de Brasília - UniCEUB. E, após a aprovação pelo CEP, o mesmo foi aplicado mantendo-se a integridade, individualidade e inviolabilidade dos dados obtidos a partir dos sujeitos de pesquisa. O projeto foi aprovado em 10 de Dezembro de 2015, recebendo o CAAE: 51119215.0.0000.0023, sob o parecer número 1.360.268.

\subsection{Local}

Tanto a coleta de sangue, processamentos e análises dos resultados foram feitas nos laboratórios do Labocien do UniCEUB, após anuência da coordenação da respectiva unidade.

\subsection{Avaliação do questionário}

Os sujeitos da pesquisa responderam um questionário visando 0 levantamento de possíveis padrões alimentares e regularidade na prática de atividades físicas, além do cálculo de IMC (Anexo I).

\subsection{Aferição da pressão arterial}

A aferição da pressão arterial foi feita pela utilização de um monitor de pressão arterial de pulso automático.

Primeiramente o voluntário sentou-se de forma ereta. A braçadeira do aparelho foi colocada ao redor o pulso esquerdo (de forma que não cobriu a região proeminente da ulna), deixando que o polegar ficasse para cima. Após o ajuste da braçadeira, foi instruído que participante cruzasse o braço sobre o peito, fazendo com que o aparelho ficasse linear ao coração. Apertou-se o botão indicado para início da averiguação, e após alguns instantes foi anotado o valor que apareceu na tela do instrumento. 


\subsection{Coleta se sangue}

Para a realização de todos os exames foram coletados um total de três tubos de sangue (aproximadamente $15 \mathrm{~mL}$ de volume total), dois tubos de EDTA, que foram destinados à extração do material genético e avaliação hematológica, e um tubo com gel, para os exames bioquímicos, de um total de 20 indivíduos.

A coleta foi feita pela punção de uma veia superficial na fossa antecubital do braço esquerdo ou direito.

\subsection{Grupo de estudo}

Os sujeitos de pesquisa foram voluntários da comunidade acadêmica do Centro Universitário de Brasília (UniCEUB) recrutados conveniência convite por escrito ou oral. Fatores de riscos e benefícios foram propostos, além de critérios de inclusão e exclusão.

- Riscos: negação dos sujeitos em participar da pesquisa, casos de malestar ou desconforto durante a coleta de sangue.

- Benefícios: Levantamento da frequência dos três tipos de polimorfismo que o gene da ECA apresenta além contagem de eritrócitos e outros fatores bioquímicos.

- Inclusão: ser hipertenso ou possuir pressão sanguínea levemente elevada e ter concordado com o termo de consentimento.

- Exclusão: Indivíduos que não correspondessem a ficha de avaliação recebida entregue antes dos procedimentos ou recusa em assinar o termo de consentimento.

\subsection{Procedimento para extração de DNA genômico dos leucócitos}

A extração do DNA genômico de leucócitos foi realizada segundo o método descrito por Miller et al. (1988), com algumas modificações.

Foram coletados cerca de $5,0 \mathrm{~mL}$ de sangue periférico e transferidos para dois tubos de $15 \mathrm{~mL}$ estéreis (2,5 mL em cada tubo) com adição de tampão lise I gelado até completar o volume de $12,5 \mathrm{~mL}$. Após homogeneizar, a solução foi centrifugada a $3200 \mathrm{rpm}$ por 5 minutos, a $4{ }^{\circ} \mathrm{C}$. O sobrenadante resultante foi desprezado e 2,25 mL de tampão lise II será adicionado ao sedimento, para 
ressuspender o precipitado; seguido de $62,5 \mu \mathrm{L}$ de SDS $10 \%$. Após agitação vigorosa por 10 segundos em temperatura ambiente, $1,0 \mathrm{~mL}$ de $\mathrm{NaCl} 6 \mathrm{~mol} / \mathrm{L}$ foi adicionado e a mistura resultante foi novamente agitada e centrifugada a $2600 \mathrm{rpm}$ em temperatura ambiente por 5 minutos. $O$ sobrenadante foi derramado em tubo limpo de $15 \mathrm{~mL}$, evitando o pellet. Após adição de $3,5 \mathrm{~mL}$ de isopropanol absoluto o tubo foi fechado e a mistura realizada por inversão. O DNA precipitado foi removido para um tubo de eppendorf, retirando o excesso de isopropanol. O DNA será lavado com $1,0 \mathrm{~mL}$ de etanol absoluto a $75 \%$, centrifugado a $5000 \mathrm{rpm}$, por 5 minutos.

Este procedimento foi repetido e o excesso de etanol, removido cuidadosamente. O DNA secou a temperatura ambiente e ressuspenso em $200 \mu \mathrm{L}$ de água milli-Q autoclavada para realização dos procedimentos descritos a seguir.

\subsection{Diagnóstico da mutação da ECA}

A presença da mutação ECA foi determinada pela amplificação de um fragmento do íntron 16 do gene que codifica a enzima conversora de angiotensina pela reação em cadeia da polimerase (PCR).

$O$ polimorfismo da ECA foi determinado através de PCR, utilizando primers que reconhecem sequências comuns aos dois alelos (D e I) (direto: 5' CTG GAG ACC ACT CCC ATC CTT TCT 3'; reverso: 5' GAG GTG GCC ATC ACA TTC GTC AGAT 3'), gerando amplicons de 480 pb para a variante alélica I e de 190 pb para a variante $\mathrm{D}$. O volume total da reação foi $25 \mu \mathrm{L}$, contendo $2 \mathrm{mM} \mathrm{MgCl}_{2}, 2 \mathrm{mM}$ Tris- $\mathrm{HCl}$ $\mathrm{pH} 8,4,5 \mathrm{mM} \mathrm{KCl}, 20 \mathrm{pmol}$ de cada primer (IDT), $200 \mu \mathrm{M}$ da mistura de dNTPs (Invitrogen), 1\% DMSO (Sigma), 1U Taq DNA polimerase (Invitrogen). As condições da reação foram: desnaturação inicial a $94{ }^{\circ} \mathrm{C}$ por 3 minutos, 30 ciclos com desnaturação a $94{ }^{\circ} \mathrm{C}$ por 1 minuto, anelamento a $52{ }^{\circ} \mathrm{C}$ por 1 minuto e extensão a $72{ }^{\circ} \mathrm{C}$ por 1 minuto, extensão final a $72{ }^{\circ} \mathrm{C}$ por 5 minutos (Rigat, 1992). A visualização dos amplicons foi realizada por meio de eletroforese em gel de agarose $1,5 \%$ contendo $0,5 \mu \mathrm{g} / \mu \mathrm{L}$ de brometo de etídio, seguida de observação em luz ultravioleta. 


\subsection{Contagem de hemácias}

Para a contagem de hemácias, primeiro foi preparada uma diluição de $10 \mu \mathrm{L}$ de sangue em 1,99 mL de liquido de Hayem (Diluição final 1:200). As células foram contadas na câmara de Neubauer. A contagem foi feita em cinco grupos de quadrados. Para o cálculo final do número de eritrócitos por $\mathrm{mm}^{3}$ de sangue, o número de eritrócitos contados foi multiplicado por $10.000(5 \times 10 \times 200=10.000)$.

\subsection{Dosagem de hemoglobina}

Para a dosagem de hemoglobina foram utilizados $5 \mathrm{~mL}$ do reagente de cor e $20 \mu \mathrm{L}$ do sangue total. A absorbância foi lida em espectrofotômetro em $540 \mathrm{~nm}$.

Para o cálculo do fator foi empregada a fórmula: Fator $(F)=$ valor do padrão/absorbância do padrão.

Em para o cálculo da hemoglobina foi utilizada a fórmula $\mathrm{Hg}(\mathrm{g} / \mathrm{dl})=$ absorbância T x Fator (F).

\subsection{Contagem diferencial dos leucócitos}

O distendido sanguíneo para contagem de células leucocitárias foi feito com uma gota do sangue coletado no tubo contendo anticoagulante. A lâmina foi corada com coloração hematológica panótica e levada para visualização em microscópio óptico. Foram então contadas 100 células, diferenciando-as entre neutrófilos, basófilos, eosinófilos, linfócitos e monócitos. O número de células foi transformado em porcentagem.

\subsection{Dosagens bioquímicas}

O procedimento para glicose, uréia, creatinina e ácido úrico foram realizados de acordo com as instruções do fabricante conforme orientações descritas na bula dos diferentes kits.

\subsection{Destino das amostras}

Após a conclusão do projeto todo o DNA coletado foi destruído por método que garanta a sua inviabilidade funcional. 


\section{Resultados e discussão}

Inicialmente 20 estudantes do UniCEUB foram selecionados de forma aleatória por meio de convite. Os interessados em participar da pesquisa foram direcionados ao Labocien para assinarem o Termo de Consentimento Livre e Esclarecido, responder o questionário, fazer a aferição da pressão arterial e realização da coleta de sangue. Aos participantes que desistiram durante a coleta ou que não compareceram quando convocados para recoleta, os documentos assinados e material colhido foram descartados e novos participantes selecionados. Após a coleta de sangue o participante foi liberado. Ao total foram avaliadas 12 mulheres e 8 homens, sendo a média de idade entre os participantes foi de 21 (2823).

Após a coleta de sangue, um dos tubos de EDTA foi destinado para a extração do DNA, outro para as análises hematológicas e o tubo com gel para a análise bioquímica, sendo que os resultados podem ser observados na tabela 1.

Tabela 1- Resultado das dosagens bioquímicas e hematológicas obtidas de 20 participantes da pesquisa membros da comunidade acadêmica do UniCEUB.

Testes realizados

Dosagem de hemoglobina

Contagem diferencia de leucócitos

Contagem global de hemácias

Dosagem de glicose

Dosagem de urato

Dosagem de Triglicerídeos
Resultados*

Homens: 12,7 - 18,0 g/dL

Mulheres: 10,7 - 15,4 g/dL

Neutrófilos: 50 - 70\%

Linfócitos: $20-40 \%$

Monócitos: 2 - 10\%

Eosinófilos: 2 - 8\%

Basófilos: $0-3 \%$

Homens: 4,5 - 6 milhões $/ \mathrm{mm}^{3}$

Mulheres: 4 - 5, 5 milhões $\mathrm{mm}^{3}$

$$
70-99 \mathrm{mg} / \mathrm{dL}
$$

Homens: 2,5 - 7,0 mg/dL

Mulheres: $1,6-6,0 \mathrm{mg} / \mathrm{dL}$

Menor que $150 \mathrm{mg} / \mathrm{dL}$

- Os valores de referência foram inseridos pois demonstram que todos os pacientes avaliados estavam dentro dos padrões de normalidade para cada teste. 
O perfil dos valores obtidos na aferição da pressão arterial dos participantes estava dentro do valor de referência preconizado pelo Instituto Nacional de Cardiologia Preventiva (2011), sendo menor ou igual a $120 \times 80 \mathrm{mmHg}$.

A análise do perfil genético para a presença do polimorfismo, associado aos testes bioquímicos, hematológicos e a aferição da pressão arterial dos voluntários constatou que esses estavam saudáveis e eram normais para a característica pesquisada. Porém na avaliação do questionário foi observado que todos os participantes integram algum grupo de risco para o desenvolvimento da hipertensão.

A maioria dos entrevistados relatou casos de hipertensão na família (gráfico 1). Ainda que a presença do polimorfismo de deleção da ECA não esteja presente, outras interferências genéticas devem ser investigadas. Para Fermino et al (2009) a hipertensão possui uma patogenia complexa sendo resultado de fatores genéticos, ambientais e demográficos.

Gráfico 1 - Porcentagem de casos de hipertensão na família do participante da pesquisa*.

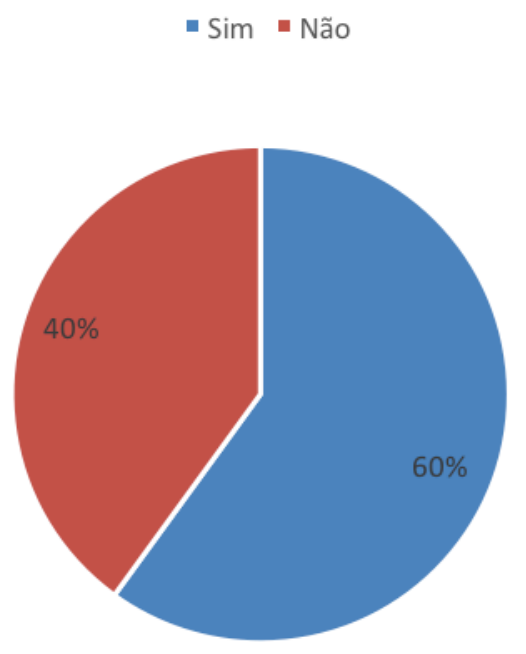

Kimura (2010) classifica geneticamente a hipertensão em dois grupos. O primeiro é a hipertensão hereditária monogênica e corresponde a menos de $1 \%$ dos casos. O autor cita casos como a síndrome de Liddle (16p13), síndrome de Gordon (12p13 e 17q21) e o hiperaldoteronismo familiar II (7p22), no qual o principal sinal clínico é a hipertensão. O segundo grupo, chamado de hipertensão essencial é caracterizado por ser de herança poligênica. Nesses casos, genes relacionados com 
o sistema renina-angiotensina-aldosterona e proteínas regulatórias de sinalização das proteínas $G$, por exemplo, seriam possíveis candidatos.

A origem complexa da hipertensão não é restrita pelos fatores genéticos e, sim, uma associação desses com o ambiente (FERMINO et al. 2009). Machado; Pires; Lobão (2011) classificam os fatores de risco para ocorrência da doença como não modificáveis e modificais. Dentro do primeiro entram não apenas a genética do paciente, mas também o sexo e a idade. Fatores modificáveis estão relacionados com qualidade de vida dos indivíduos, obesidade, sedentarismo e ingestão excessiva de sal.

Apenas $10 \%$ dos entrevistados afirmaram que se exercitam com relativa frequência (duas vezes por semana) enquanto que a metade disse que raramente pratica algum exercício físico, como pode ser observado no gráfico 2. Aziz (2014) relaciona a inatividade física como uma consequência do progresso moderno. Segundo o autor, o êxodo para os centros tecnológicos e a busca pelo conforto foram responsáveis por tornar o sedentarismo um problema de saúde pública, chegando a afirmar que se trata de uma pandemia.

Gráfico 2 - Frequência de prática de atividade física dos participantes da pesquisa.

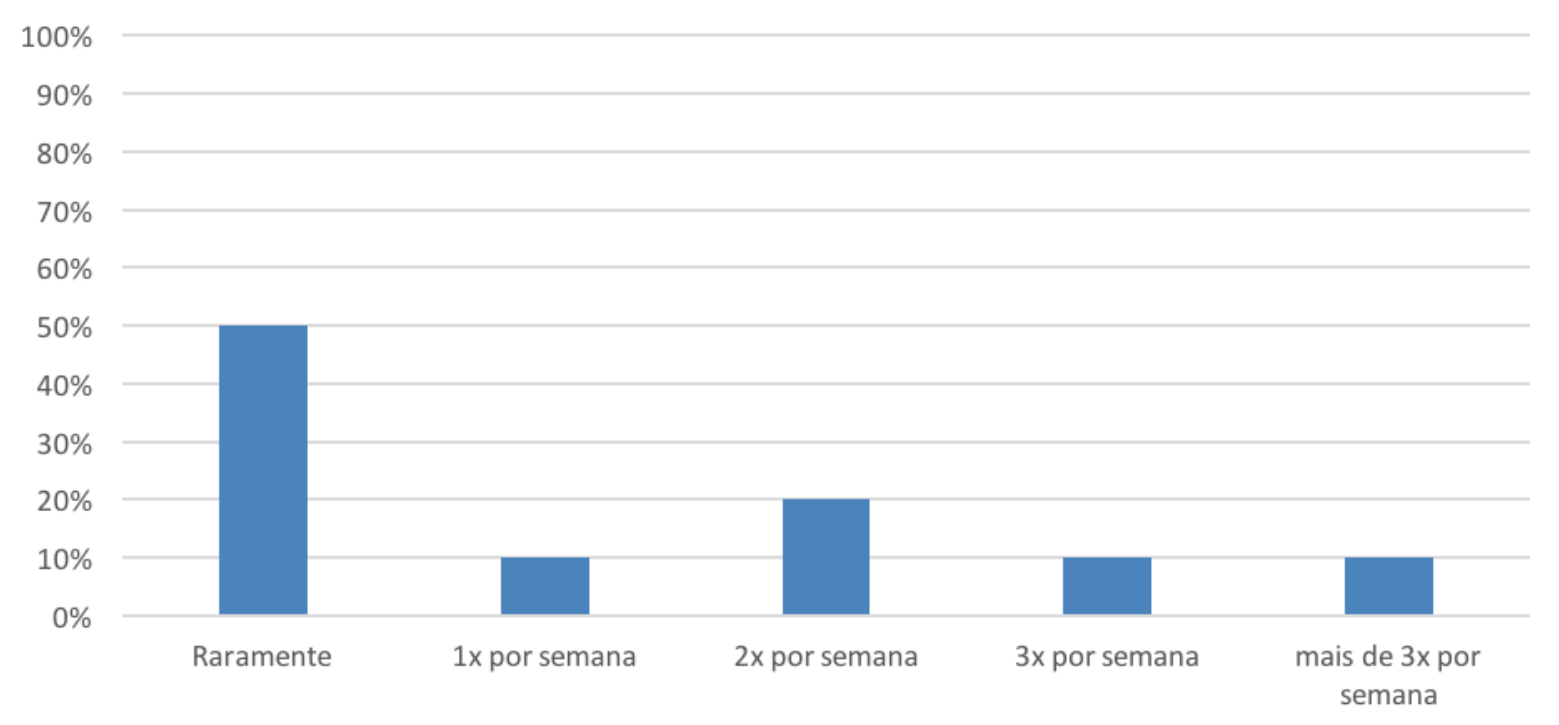

De acordo com Carlucc et al. (2013) a falta de atividade física constitui o grupo de fatores críticos para o aparecimento de doenças cardiovasculares e é responsável por $80 \%$ dos casos de desses agravos. Dentro desse grupo, Azis 
(2014) completa, pontuando que a falta de atividade física está fortemente associada a hipertensão.

Os efeitos do sedentarismo ultrapassam o âmbito da saúde pública, chegando a afetar, até mesmo, a economia do pais. Bielemann; Knuth; Hallal (2009) constataram que mais de 2 bilhões de reais seriam economizados pelo estado com internações e compra de remédios anualmente caso a população sedentária adotasse práticas ativa. Dentro do grupo de pacientes hipertensos, a economia seria de 13 mil dos 100 mil reais gastos na compra de medicamentos.

O IMC (Índice De Massa Corporal) dos participantes foi analisado de acordo com o guia: Atualização das Diretrizes para o Tratamento Farmacológico da Obesidade e do Sobrepeso (ABESO, 2010) e demonstrou que a maioria estava com seu peso ideal (tabela 3). Amer; Marcon; Santana (2010) consideram o cálculo desde indicador importante, uma vez que, a obesidade pode ser considerada um fator importante para a ocorrência da hipertensão. No estudo feito por Neto et al. (2008), o cálculo do IMC, associado a averiguação da circunferência da cintura estão fortemente relacionados a doença, principalmente em jovens do sexo masculino. Os autores concluem que o aprimoramento do sistema cardiorrespiratório desde a infância interfere na gênese não apenas da hipertensão, mas também de outras doenças cardiorrespiratórias.

Tabela 3 - Classificação do cálculo do IMC dos participantes da pesquisa.

IMC

Número de indivíduos

\begin{tabular}{|c|c|}
\hline Abaixo do peso & 2 \\
\hline Peso normal & 14 \\
\hline Pré-obeso & 2 \\
\hline Obeso I & 2 \\
\hline
\end{tabular}

A mudança nos hábitos alimentares deve ser considerada um importante fator que interfere na gênese da hipertensão (JARDIM et al., 2007). Mais da metade dos pesquisados relatou que costuma se alimentar de comidas do tipo fast food e oito adicionam sal nos alimentos ou outros molhos industrializados. Frutas e legumes são consumidos com frequência por metade dos pesquisados e nove participantes se integram salada com regularidade a dieta (gráfico 3). 
Gráfico 3 - Descrição dos hábitos alimentares dos participantes da pesquisa.

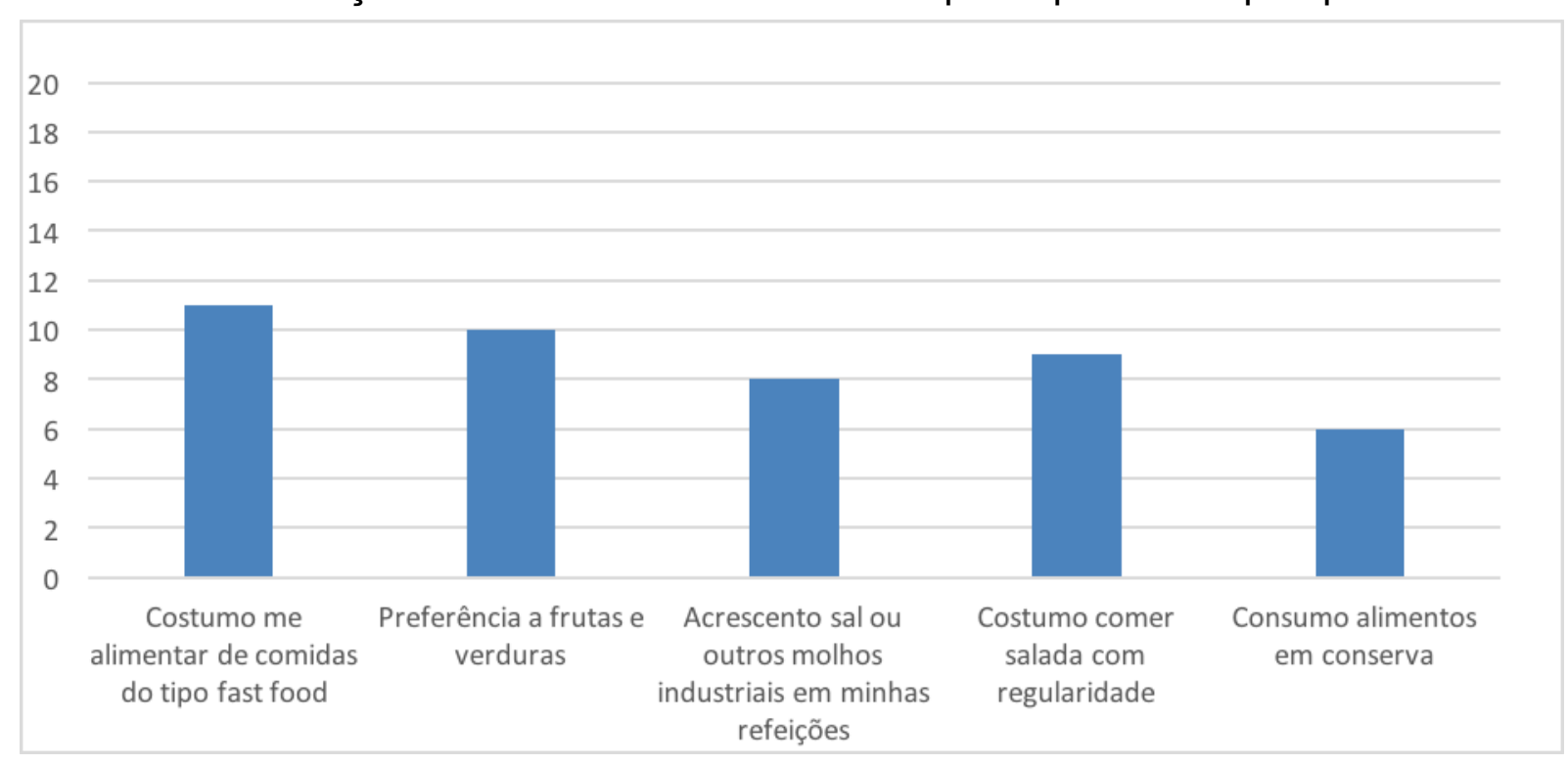

Nesta questão é importante destacar a presença do sal comum, cloreto de sódio, nos alimentos que de acordo com Bombig; Francisco; Machado (2014) é composto por dois importantes agentes que interferem na hemostasia do organismo. Quando ingeridos em altas quantidades eles provocam aumento do volume e pressão sanguínea, além de serem relacionados com casos de hipertrofia de cardiomiócitos. Os autores destacam que grupos de risco como pacientes com idade avançada, obesos, portadores de síndrome metabólica possuem maior sensibilidade ao sal, fator que contribui para uma chance maior de desenvolverem hipertensão.

Sarno et al. (2013) observaram que a quantidade de sal ingerida pela população brasileira nos anos de 2008 a 2009 foi de 4,7 g/dia, ou seja, maior que o dobro do recomendado pela OMS (Organização Mundial da Saúde), 2 g/dia. Eles ainda constaram que o aumento na disponibilidade de sódio é oriundo da popularização dos alimentos processados.

De acordo com a Sociedade Brasileira de Hipertensão (2016), o consumo diário de água deve ser entre $2 \mathrm{~L}$ a $2,5 \mathrm{~L}$. Observou-se, portanto, que apenas $20 \%$ dos entrevistados estão próximos a essa marca (Gráfico 4). 
Gráfico 4 - Frequência de ingestão de água pelos participantes da pesquisa.

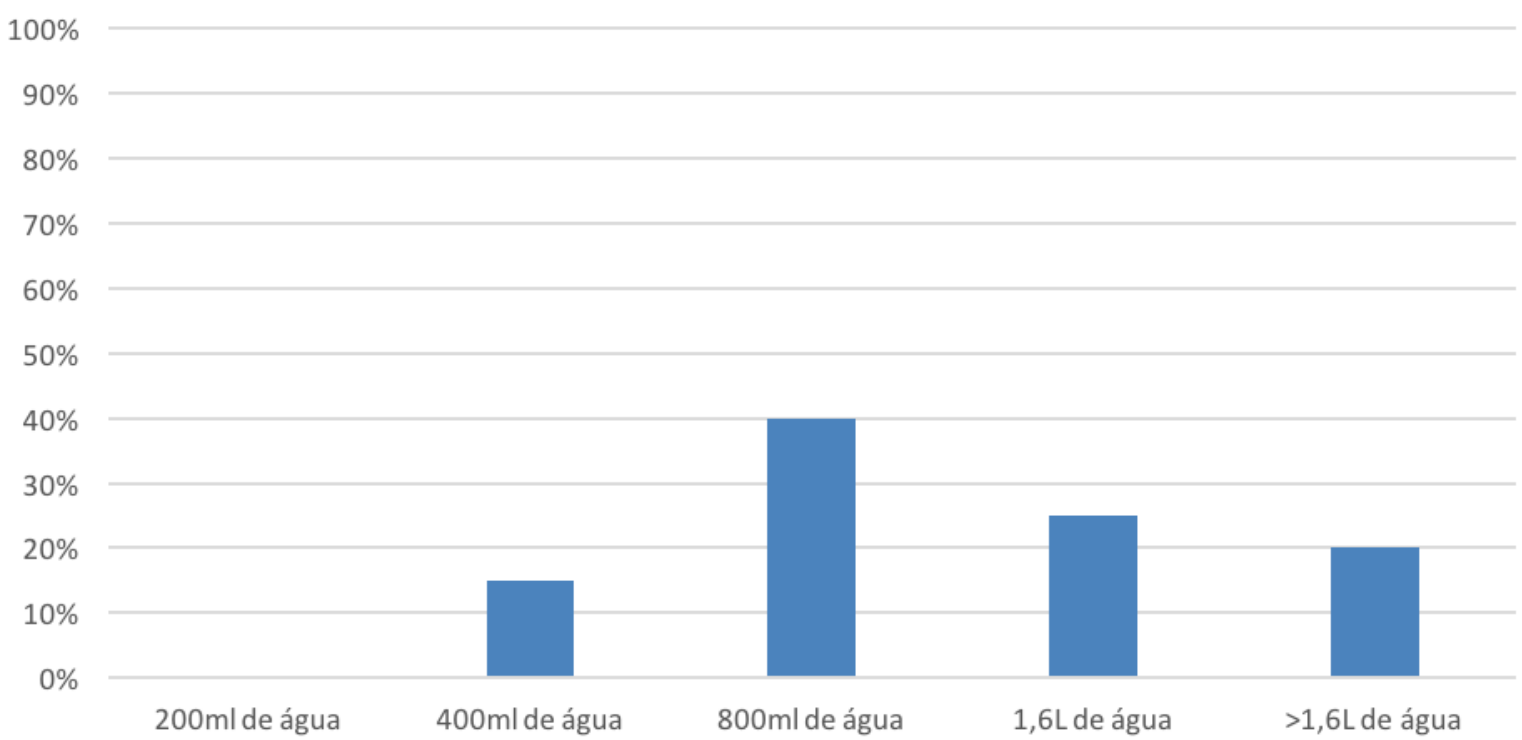

Quase todos os participantes declararam não ingerem bebida alcoólica (gráfico 5). A relação do álcool com a hipertensão depende da quantidade ingerida (VI DIRETRIZES BRASILEIRAS DE HIPERTENSÃO, 2010). Souza (2014) afirma que o consumo excessivo de álcool seja responsável de $10 \%$ a $30 \%$ dos casos de hipertensão. Após a ingestão de etanol ocorre uma resposta bifásica do organismo, primeiramente por uma vasodilatação, provocada pela atividade simpática, e uma resposta mais tardia de vasoconstrição, relacionada aos barorreceptores. Porém este último processo ainda não foi totalmente esclarecido.

Gráfico 5 - Frequência de ingestão de álcool pelos 20 participantes da pesquisa.

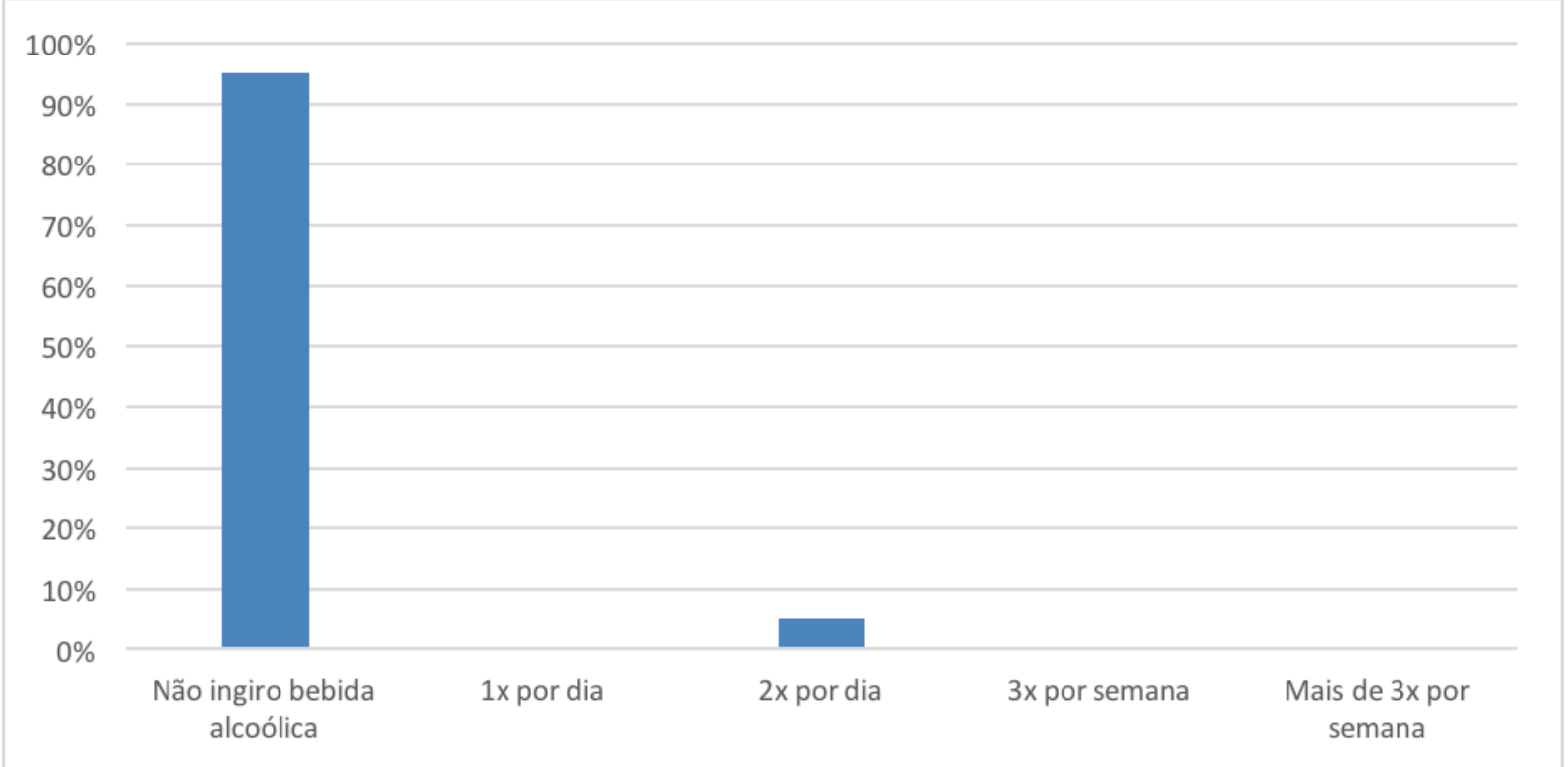


Na análise do gene ECA foram encontrados 3 genótipos (DI, II, DD) conforme a figura 1. Dos 20 participantes da pesquisa analisados, observou-se que a distribuição dos genótipos foi: DD (16,7\%), DI (55,5\%) e II (27,8\%), não apresentando diferença significativa na distribuição $(p<0,05)$. A frequência alélica observada para a variante alélica $D$ foi de 0,44 e para a variante I foi de 0,56.

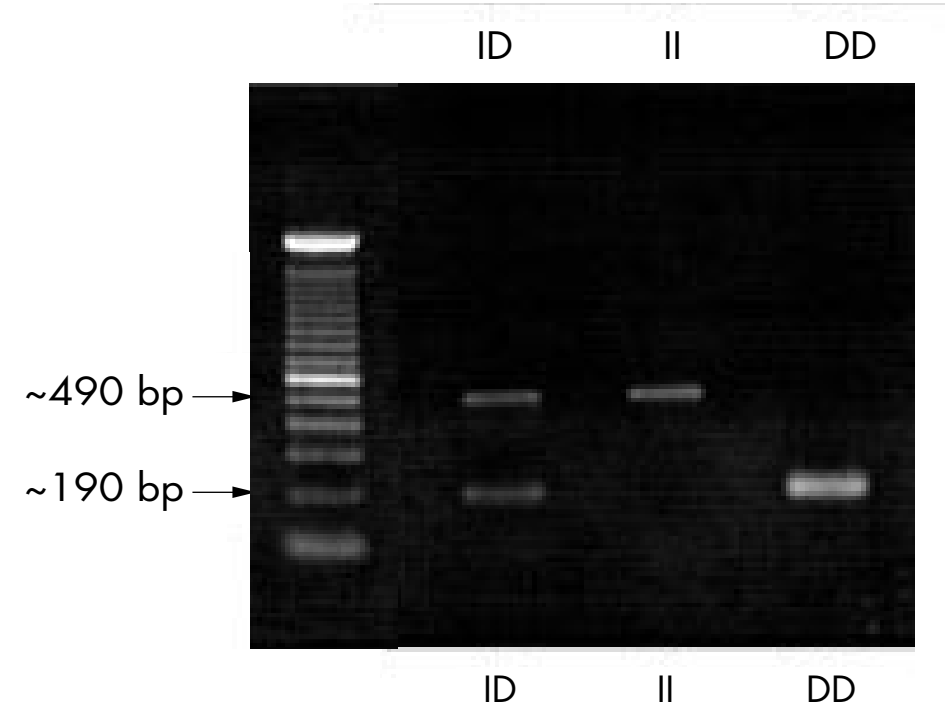

Figura 1 - Gel de agarose corado com brometo de etídio revelando o perfil de amplificação dos alelos I (490pb) e D (190pb) e os respectivos genótipos (DI, II e DD).

Os resultados obtidos nesse trabalho muita podem, em parte, ser explicados pelo tamanho relativamente pequeno das amostras, ou seja, um poder inadequado para detectar modestas contribuições de um fator genético individual para traços complexos (Sayed-Tabatabaei et al., 2004).

Outro fator que pode contribuir para os resultados obtidos pode estar relacionado ao fator étnico que não foi considerado nesse estudo. As freqüências dos diferentes marcadores podem variar de acordo com a estrutura da população e a etnia. Assim, em razão das diferenças genéticas interindividuais ou do estilo de vida, um fator que é identificado como de risco para uma população pode não ser significante em outro grupo populacional (Ruppert; Maisch, 2003).

A interação gene-ambiente também pode ser responsável por uma parcela das alterações entre os estudos. Fatores ambientais ou comportamentais como o exercício físico e o cigarro podem influenciar a expressão de um determinado gene e assim influenciar o fenótipo final. Existem evidências de que a nicotina aumenta a 
expressão de vários genes no endotélio, incluindo o gene da ECA (SayedTabatabaei et al., 2004).

Contudo, nesse estudo não foi possível correlacionar qualquer dos fatores bioquímicos e hematológicos com os genótipos da ECA.

\section{Considerações finais}

O sistema renina-angiotensina-aldosterona é um exemplo de como o corpo integra os sistemas a fim de manter o organismo em equilíbrio. Estudar a influência do polimorfismo da enzima conversora de angiotensina na ocorrência da hipertensão se faz importante pois milhões de pessoas sofrem com esse agravo e muitas vezes não são diagnosticadas.

A utilização de metodologias moleculares para investigação de outros fatores genéticos relacionados a esse agravo devem ser sempre utilizados, uma vez a doença é de origem multifatorial, na maioria das vezes sendo resultado de interferências ambientais e genotípicas.

É importante ressaltar que fatores relacionados a qualidade de vida interferem fortemente na ocorrência da hipertensão. A promoção de hábitos saudáveis como prática de atividade física e alimentação balanceada deve ocorrer tanto em grupos de risco como em indivíduos hígidos.

As análises bioquímicas e hematológicas pouco se relacionaram com a presença do polimorfismo da ECA, sendo o diagnóstico molecular de maior precisão, devendo ser implantado na triagem clínica de todos os pacientes com suspeita do agravo.

Com relação ao polimorfismo observou-se a detecção dos três genótipos mas não foi possível correlacionar os genótipos com qualquer fator avaliado.

\section{Referências}

ABESO. Atualização das diretrizes para o tratamento Farmacológico da obesidade e do sobrepeso. Out 2010. Disponível em < http://www.abeso.org.br/plugins/ckeditor/ckfinder/userfiles/files/diretrizes2010\%5B1\% 5D.pdf> Acesso em 24 de agosto de 2016. 
ALMEIDA, B. V. P. et al. Associação da hipertensão arterial com polimorfismo da enzima conversora da angiotensina em indivíduos idosos*. Revista Brasileira De Clínica Médica. Vol. 8, n. 4, p. 320-322, 2010. Disponível em < http://files.bvs.br/upload/S/1679-1010/2010/v8n4/a006.pdf > Acesso em 10 de fevereiro de 2016

AMER, Nadia Mohamed; MARCON, Sonia Silva; SANTANA, Rosangela Getirana. Índice de massa corporal e hipertensão arterial em indivíduos adultos no CentroOeste do Brasil. Arq. Bras. Cardiol. São Paulo, v. 96, n. 1, p. 47-53, jan. 2011. Disponível em <http://www.scielo.br/scielo.php?script=sci_arttext\&pid=S0066782X2011000100009\&Ing=en\&nrm=iso> Acesso em 24 de agosto de 2016.

AZIZ, J. L. Sedentarismo e hipertensão arterial. Revista Brasileira de Hipertensão. V. 21, n. 2, p. 75-82, 2014. Disponível em < http://departamentos.cardiol.br/sbcdha/profissional/revista/21-2.pdf> Acesso em 22 de agosto de 2016.

BIELEMANN, R. M., KUNTH, A. G., HALLAL, P. C. Atividade física e redução de custos por doenças crônicas ao Sistema Único de Saúde. Revista Brasileira de Atividade Física \& Saúde. V.15, n. 1, p. 9-14, 2010. Disponível em < https://periodicos.ufpel.edu.br/ojs2/index.php/RBAFS/article/view/674/689> Acesso em 21 de agosto de 2016.

BOMBIG, M. T. N., FRANCISCO, Y. A., MACHADO, C. A. A importância do sal na origem da hipertensão. Revista Brasileira de Hipertensão. V. 21, n. 2, p. 63-67, 2014. Disponível em $<$ http://departamentos.cardiol.br/sbcdha/profissional/revista/21-2.pdf> Acesso em 22 de agosto de 2016.

BUENO, S. et al. Relação entre o polimorfismo da ECA e aptidão física. ACTA Brasileira Do Movimento Humano. V. 3, n. 2, p. 43-57, abr - jun 2013. Disponível em:

<http://www.revista.ulbrajp.edu.br/ojs/index.php/actabrasileira/article/viewFile/2086/6 20> Acesso em 13 de agosto de 2016. 
CARLUCCI, E. M. S. et al. Obesidade e sedentarismo: fatores de risco para doença cardiovascular. Comunicação em ciência da saúde. V. 24, n. 4, p. 375-384, outdez 2013.

Disponível em

http://www.escs.edu.br/pesquisa/revista/2013Vol24_4_7_ObesidadeSedentarismo.p df $>$ Acesso em 22 de agosto de 2016.

COSTA, A. M. et al. Efeitos do sistema renina-angiotensina-aldosterona e do polimorfismo I/D do gene da ECA no desempenho esportivo. Revista Brasileira de Ciências do Esporte. V. 31, n. 1, set. 2009. Disponível em: < http://revista.cbce.org.br/index.php/RBCE/article/view/629/389> Acesso em 8 de abril de 2015

FERMINO, R. C. et al. Fatores genéticos e variabilidade na pressão arterial. Uma breve revisão da literatura. Rev. bras. cineantropom. desempenho hum. V. 11, n. 3, p. 341-349, 2009. Disponível em < https://periodicos.ufsc.br/index.php/rbcdh/article/viewFile/19800037.2009v11n3p341/10337> Acesso em 24 de agosto de 2016.

FREITAS, A. I. et al. RAS gene polymorphisms, classical risk factors and the advent of coronary artery disease in the Portuguese population. BCM Cardiovascular Disorders. Vol 8, n. 15, jul 2008. Disponível em <http://bmccardiovascdisord.biomedcentral.com/articles/10.1186/1471-2261-815\#CR34_195> Acesso em 10 de fevereiro de 2016

FREITAS, S. R. S. et al. Análise combinada de fatores genéticos e ambientais na hipertensão essencial em um município da região Amazônica. Arquivos Brasileiros de Cardiologia. São Paulo, vol. 88, n. 4, p. 447-451, abr. 2007. Disponível em $<$ http://www.scielo.br/scielo.php?script=sci_arttext\&pid=S0066782X2007000400014> Acesso em 9 de fevereiro de 2016.

GAMA, G. G. G.; MUSSI, F. C.; GUIMARÃES, A. C. Revisando os fatores de risco cardiovascular. Revista de Enfermagem UERJ. Rio de Janeiro, vol. 18, n. 4, p. 650655, out/dez 2010. Disponível em <http://www.facenf.uerj.br/v18n4/v18n4a25.pdf > Acesso em 22 de agosto de 2016. 
HOUCHER B. et al. Prevalence of genetic polymorphisms of methylenetetrahydrofolate reductase C677T and angiotensin I-converting enzyme (insertion/deletion) in Sétif population, Algeria. Molecular Biology Research Communications. Vol. 2, n. 1-2, p. 19-27, abr. 2013. Disponível em <http://mbrc.shirazu.ac.ir/article_1469_346.html > Acesso em 10 de fevereiro de 2016.

INSTITUTO NACIONAL DE CARDIOLOGIA PREVENTIVA. Hipertensão. 2011. Disponível em <http://www.incp.pt/conselhos/sobre-a-hipertensao-arterial> Acesso em 25 de agosto de 2016.

JARDIM, Paulo César B. Veiga et al. Hipertensão arterial e alguns fatores de risco em uma capital brasileira. Arq. Bras. Cardiol., São Paul. V. 88, n. 4, p. 452-457, abr. $2007 . \quad$ Disponível em <http://www.scielo.br/scielo.php?script=sci_arttext\&pid=S0066782X2007000400015\&lng=pt\&nrm=iso> Aceso em 23 de agosto de 2016.

JUNIOR, M. C. A., ABRAMOV, D. M. Fisiologia Essencial. Rio de Janeiro: Guanabara Koogan, 2011.

Kimura, L. Fatores genéticos associados à hipertensão essencial em populações remanescentes de quilombos do Vale do Ribeira - São Paulo. Tese (Doutorado) Universidade de São Paulo, Instituto de Biociências, São Paulo, 2010.

KOHLMANN JUNIOR, O. et al. Tratamento medicamentoso. Jornal Brasileiro de Nefrologia. São Paulo, vol. 32, supl. 1, p. 29-43, set. 2010. Disponível em <http://www.scielo.br/scielo.php?script=sci_arttext\&pid=S010128002010000500008> Acesso em 10 de fevereiro de 2016

MACHADO, M. C.; PIRES, C. G. S.; LOBAO, W. M. Concepções dos hipertensos sobre os fatores de risco para a doença. Ciênc. saúde coletiva, Rio de Janeiro , v. 17, n. 5, p. 1357-1363, maio 2012 . Disponível em <http://www.scielosp.org/scielo.php?script=sci_arttext\&pid=S1413$81232012000500030 \&$ Ing=en\&nrm=iso>. Acesso em 23 de agosto de 2016. 
MILLER S. A.; DYKES D. D.; POLESKY H. F. A simple salting out procedure for extracting DNA from human nucleated cells. US National Library of Medicine; 1988.

em:

<http://www.ncbi.nlm.nih.gov/pmc/articles/PMC334765/?page=1> Acesso em 5 de maio de 2015

NLH, U.S. NATIONAL LIBRARY OF MEDICINE. ACE- Angiotensin I converting enzyme. Disponível em <https://ghr.nlm.nih.gov/gene/ACE\#location> Acesso em 13 de agosto de 2016.

NOGUEIR, A. A. R. Estudo dos efeitos da bradicinina sobre a função renal de ratos. 05 de abril de 2011. 115 f. Dissertação (Mestrado) - Universidade Estadual do Centro de Ciências da Saúde da Universidade Estadual do Ceará, Fortaleza, 2011.

PAHO. Dia mundial da hipertensão 2015. Disponível em < http://www.paho.org/bireme/index.php?id=286\%3Adia-mundial-da-hipertensao2015\&option=com_content $>$ Acesso em 21 de agosto de 2016.

RADOVANOVIC, C. A. T. et al. Hipertensão arterial e outros fatores de risco associados às doenças cardiovasculares em adultos. Revista Latino-Americana de Enfermagem. Ribeirão Preto, v. 22, n. 4, p. 547-553, aug. 2014 . Disponível em <http://www.scielo.br/scielo.php?script=sci_arttext\&pid=S010411692014000400547\&Ing=en\&nrm=iso> Acesso em 22 de agosto de 2016.

RAMACHANDRAN, V. et al. Association of insertion/deletion polymorphism of angiotensin-converting enzyme gene with essential hypertension and type 2 diabetes mellitus in Malaysian subjects. Journal of Renin-Angiotensin-Aldosterone System. Vol. 8, n. 4, p. 208-214, dez. 2008. Disponível em < http://jra.sagepub.com/content/9/4/208.long> Acesso em 10 de fevereiro de 2016.

RIBEIRO, J. M. Inibidores da enzima conversora da angiotensina e bloqueadores de receptores da angiotensina II no tratamento da hipertensão arterial. Hipertensão. Vol. 5, n. 2, p. 69-72, 2002. Disponível em < 
http://sbh.org.br/revistas/2002_N2_V5/69a72.pdf> Acesso em 10 de fevereiro de 2016

SAMPAIO, W. O.; PINHEIRO, S. V; SANTOS, R. A. S. Aspectos fisiológicos e fisiopatológicos do sistema renina-angiotensina: Ênfase na função vascular. Hipertensão. V. $12, \quad$ n. 2 , $\quad$ p. 44-50. 2009. Disponível em < http://www.sbh.org.br/revistas/2009/revista_hipertensao_02_2009.pdf> Acesso em 13 de agosto de 2016.

SANJULIANI, A. F. et al. Eixo renina-angiotensina-aldosterona: bases fisiológicas e fisiopatológicas. Revista Hospital Universitário Pedro Ernesto. V. 10, n. 3, p. $20-$ 30, 2011. Disponível em < http://revista.hupe.uerj.br/detalhe_artigo.asp?id=90\#citar> Acesso em 13 de agosto de 2016.

SARNO, Flavio et al. Estimativa de consumo de sódio pela população brasileira, 2002-2003. Rev. Saúde Pública, São Paulo. V. 43, n. 2, p. 219-225, apr. 2009. Disponível em <http://www.scielo.br/scielo.php?script=sci_arttext\&pid=S0034$89102009000200002 \&$ Ing=en\&nrm=iso> Acesso em 24 de agosto de 2016.

SAYED-TABATABAEI, F.A.; SCHUT, A.F.C.; HOFMAN, A.; BERTOLI-AVELLA, A.M.; VERGEER, J.; WITTEMAN, J.C.M.; et al. A study of gene-environment interaction on the gene for angiotensin converting enzyme: a combined functional and population based approach. J Med Genet. 2004; 41: 99-103.

SOCIEDADE BRASILEIRA DE HIPERTENSÃO. Beba água. São Paulo. Disponível em <http://www.sbh.org.br/ipad/noticias.php?id=439> Acesso em 24 de agosto de 2016.

SOUZA, D. S. M. Álcool e hipertensão. Aspectos epidemiológicos, fisiopatológicos e clínicos. Revista Brasileira de Hipertensão. V. 21, n. 2, p. 83-86, 2014. Disponível em < http://departamentos.cardiol.br/sbc-dha/profissional/revista/21-2.pdf> Acesso em 24 de agosto de 2016. 
STABELINI NETO, A. et al. Hipertensão arterial na adolescência: associação com a aptidão cardiorrespiratória, o IMC e a circunferência da cintura. Revista Brasileira de Hipertensão. V. 15, n. 2, p. 59-64, 2008. Disponível em < http://departamentos.cardiol.br/dha/revista/15-2/04-adolescencia.pdf> Acesso em 24 de agosto de 2016.

UNIVERSIDADE FEDERAL FLUMINENSE. Integração: Regulação da volemia e fisiopatologia da hipertensão arterial. Disponível em < http://www.uff.br/fisio6/PDF/sistema_renal/volemia_hipertensao.pdf> Acesso em 13 de agosto de 2016

VARK, L. C. van et al; Angiotensin-converting enzyme inhibitors reduce mortality in hypertension: a meta-analysis of randomized clinical trials of renin-angiotensinaldosterone system inhibitors involving 158998 patient. European Heart Journal. V. 33, n. 16, p. 2088-2097, ago. 2012. Disponível em: < http://www.ncbi.nlm.nih.gov/pubmed/22511654> Acesso em 10 de fevereiro de 2019

VI DIRETRIZES BRASILEIROAS DE HIPERTENSÃO. Conceituação, epidemiologia e prevenção primária. Revista Brasileira de Hipertensão. V. 17, n. 1, p. 7-10. 2010. Disponível em <http://departamentos.cardiol.br/dha/vidiretriz/05-cap01.pdf> Acesso em 13 de agosto de 2016.

WHO, WORLD HEALTH ORGANIZATION. A global brief on Hypertension. World Health Day 2013, 2013. Disponível em: <http://apps.who.int/iris/bitstream/10665/79059/1/WHO_DCO_WHD_2013.2_eng.pdf > Acesso em 2 de maio de 2015 


\section{Anexos}

\subsection{Anexo A - Aprovação do Comitê de Ética}

\section{PARECER CONSUBSTANCIADO DO CEP}

DADOS DO PROJETO DE PESQUISATítulo da Pesquisa: Estudo da influência do polimorfismo da enzima conversora de angiotensina em casos

de hipertensão Pesquisador: Paulo Roberto Queiroz

Área Temática: Genética Humana:(Trata-se de pesquisa envolvendo Genética Humana que não necessita de análise ética por parte da CONEP;);

Versão: 1CAAE: 51119215.0.0000.0023Instituição Proponente: Centro Universitário de Brasília - UNICEUB Patrocinador Principal: Financiamento Próprio

\section{DADOS DO PARECER Número do Parecer: 1.360.268}

\section{Apresentação do Projeto:}

A enzima conversora de angiotensina (ECA) de zinco que atua na conversão de angiotensina I em angiotensina II, além de ser o agente na inativação de bradicinina. $\mathrm{O}$ aumento na quantidade da ECA influencia no desenvolvimento de cardiopatias, como casos de hipertensão arterial, uma vez que, é um importante agente na vasoconstrição do organismo. O projeto objetiva levantar a frequência dos genes da enzima conversora de angiotensina em indivíduos normais e indivíduos hipertensos, além de relacionar hereditariedade do polimorfismo da ECA em ambos os casos. Os 30 participantes da pesquisa serão recrutados mediante convite e todos estarão na faixa etária acima dos 18 anos. A partir de um questionário inicial serão separados dois grupos, indíviduos normais e indivíduos hipertensos. O DNA será extraído a partir de amostras de sangue e será realizado um exame molecular por PCR para a detecção de variantes polimórficas da enzima E.C.A.

\section{Objetivo da Pesquisa:}

Fazer o levantamento da frequência dos genes da enzima conversora de angiotensina em indivíduos normais e indivíduos hipertensos, além de relacionar hereditariedade do polimorfismo da ECA em ambos os casos.

Endereço: SEPN 707/907 - Bloco 6, sala 6.110, 10 andarBairro: Setor Universitário CEP: 70.790-075UF: DF Município: BRASILIATelefone: (61)3966-1511 E-mail: cep.uniceub@uniceub.br

Página 01 de 04 


\section{CENTRO UNIVERSITÁRIO DE BRASÍLIA - UNICEUB}

Continuação do Parecer: 1.360 .268

\section{Avaliação dos Riscos e Benefícios:}

Os riscos são devidos à coleta do sangue da fossa cubital. Entretanto, a coleta será acompanhada pelo professor orientador e mais 2 alunos. O procedimento será realizado segundo os procedimentos operacionais padrões estabelecidos na literatura e sob a orientação do professor orientador, em meios assépticos e com uso de Equipamentos de Proteção Individual, obedecendo às normas de biossegurança. Entre os benefícios o participante da pesquisa terá como benefício à realização do hemograma e terá a oportunidade de saber se está com alguma alteração. E, sem nenhum custo, quando apresentar alteração será encaminhado ao posto de saúde.

\section{Comentários e Considerações sobre a Pesquisa:}

Pesquisa importante e com significativo mérito técnico e científico.

\section{Considerações sobre os Termos de apresentação obrigatória:}

Os termos estão apresentados de acordo com a Resolução no 466/2012 do Conselho Nacional de Saúde.

\section{Recomendações:}

Retirar do TCLE a frase: "Em caso de gravação, filmagem, fotos, explicitar a realização desses procedimentos", tendo em vista que na pesquisa não haverá nenhum desses procedimentos. Além disso, como há previsão de desconforto ou mal-estar durante a coleta de amostras, explicitar no TCLE quais medidas preventivas serão tomadas para minimizar qualquer risco ou incômodo.

O CEP-UniCEUB ressalta a necessidade de desenvolvimento da pesquisa, de acordo com o protocolo avaliado e aprovado, bem como, atenção às diretrizes éticas nacionais quanto aos incisos XI.1 e XI.2 da Resolução no 466/12 CNS/MS concernentes às responsabilidades do pesquisador no desenvolvimento do projeto:

XI.1 - A responsabilidade do pesquisador é indelegável e indeclinável e compreende os aspectos éticos e legais.XI.2 - Cabe ao pesquisador:c) desenvolver o projeto conforme delineado;

d) elaborar e apresentar os relatórios parciais e final;e) apresentar dados solicitados pelo CEP ou pela CONEP a qualquer momento;f) manter os dados da pesquisa em arquivo, físico ou digital, sob sua guarda e responsabilidade, por um período de 5 anos após o término da pesquisa;g) encaminhar os resultados da pesquisa para publicação, com os devidos créditos aos 
Endereço: SEPN 707/907 - Bloco 6, sala 6.110, 10 andarBairro: Setor Universitário CEP: 70.790-075UF: DF Município: BRASILIATelefone: (61)3966-1511 E-mail: cep.uniceub@uniceub.br

Página 02 de 04

\section{CENTRO UNIVERSITÁRIO DE BRASÍLIA - UNICEUB}

Continuação do Parecer: 1.360.268

pesquisadores associados e ao pessoal técnico integrante do projeto; eh) justificar fundamentadamente, perante o CEP ou a CONEP, interrupção do projeto ou a não publicação dos resultados.Observação: Ao final da pesquisa enviar Relatório de Finalização da Pesquisa ao CEP. O envio de relatórios deverá ocorrer pela Plataforma Brasil, por meio de notificação de evento. $O$ modelo do relatório encontra-se disponível na página do UniCEUB

http://www.uniceub.br/instituicao/pesquisa/ins030_pesquisacomitebio.aspx, em Relatório de Finalização e Acompanhamento de Pesquisa.

Conclusões ou Pendências e Lista de Inadequações:

De acordo com deliberação do colegiado, a pesquisa está em condições de ser iniciada.

\section{Considerações Finais a critério do CEP:}

Protocolo previamente avaliado por este CEP, com parecer $\mathrm{N}^{\circ} 1.356 .937 / 2015$, tendo sido homologado na 21a Reunião Ordinária do CEP-UniCEUB, em 04 de dezembro de 2015.

Este parecer foi elaborado baseado nos documentos abaixo relacionados:

\section{Situação do Parecer:}

Aprovado

\section{Necessita Apreciação da CONEP:}

Não

Endereço: SEPN 707/907 - Bloco 6, sala 6.110, 10 andarBairro: Setor Universitário CEP: 70.790-075UF: DF Município: BRASILIATelefone: (61)3966-1511 E-mail: cep.uniceub@uniceub.br

Página 03 de 04 
CENTRO UNIVERSITÁRIO DE BRASÍLIA - UNICEUB

Continuação do Parecer: 1.360 .268

BRASILIA, 10 de Dezembro de 2015

Assinado por:

Marilia de Queiroz Dias Jacome (Coordenador) 


\subsection{Anexo B- Anuência Labocien}

De: Coordenação do Labocien - Profa Magda V. C. Branco Silva

Discente (s): Nathalia Oliveira Belchior Silva e Riam Fujita Gaston

Orientador: Paulo Queiroz

Curso:

Para: Coordenadora do CEP/Uniceub - prof ${ }^{a}$ Marilia Jácome

Ref.: de $-2^{\circ} / 2015$

1. PROJETO: Estudo do polimorfismo da enzima conversora de angiotensina em casos de hipertensão.

\section{SÍNTESE DO MÉTODO:}

"[...] serão coletados um total de três tubos de sangue (aproximadamente $15 \mathrm{~mL}$ ), dois tubos de EDTA, que serão destinados à extração do material genético e avaliação hematológica, e um tubo com gel, para os exames bioquímicos, de um total de 30 indivíduos.

A coleta será feita através da punção de uma veia superficial na fossa antecubital do braço esquerdo ou direito. Os sujeitos de pesquisa serão voluntários da comunidade acadêmica do Centro Universitário de Brasília (UniCEUB). Haverá extração de DNA genômico de leucócitos será realizada segundo o método descrito por Miller et al. (1988) e a presença da mutação ECA será determinada pela amplificação de um fragmento do íntron 16 do gene que codifica a enzima conversora de angiotensina pela reação em cadeia da polimerase (PCR)[...]'

Haverá ainda hemograma e bioquímica das amostras colhidas (ver projeto).

\section{ANUÊNCIA:}

Após completa tramitação pelas demais instâncias institucionais consultivas e deliberativas, observando as regras funcionais do Labocien (prazos e disponibilidade dos materiais e espaços compartilhados) o Labocien se posiciona favorável à realização dos procedimentos de coleta e processamento de amostras da pesquisa em questão. 
Observa que se, após atualização de cotações, houver exacerbação financeira sobre o limite estabelecido pelo Edital do PIC vigente este Setor retomará com os responsáveis para discutir os novos valores.

Após término dos trâmites o pesquisador deverá realizar agendamento das atividades na secretaria do Labocien.

Magda Verçosa Carvalho Branco

Coordenadora do Labocien

Brasília, setembro de 2015. 


\subsection{Anexo C- Termo de Consentimento Livre e Declarado}

\section{Estudo do polimorfismo da enzima conversora de angiotensina em casos de hipertensão \\ Instituição dos (as) pesquisadores (as): UniCEUB \\ Pesquisador (a) responsável: Paulo Roberto Queiroz \\ Pesquisador (a) assistente: Nathalia Oliveira e Rian Fujita}

Você está sendo convidado (a) a participar do projeto de pesquisa acima citado. $\mathrm{O}$ documento abaixo contém todas as informações necessárias sobre a pesquisa que estamos fazendo. Sua colaboração neste estudo será de muita importância para nós, mas se desistir a qualquer momento, isso não causará nenhum prejuízo.

O nome deste documento que você está lendo é Termo de Consentimento Livre e Esclarecido (TCLE).

Antes de decidir se deseja participar (de livre e espontânea vontade) você deverá ler e compreender todo o conteúdo. Ao final, caso decida participar, você será solicitado a assiná-lo e receberá uma cópia do mesmo.

Antes de assinar faça perguntas sobre tudo o que não tiver entendido bem. A equipe deste estudo responderá às suas perguntas a qualquer momento (antes, durante e após o estudo).

\section{Natureza e objetivos do estudo}

- O objetivo específico deste estudo é fazer o levantamento da frequência dos genes da enzima conversora de angiotensina (ECA) em indivíduos normais e indivíduos hipertensos, além de relacionar casos de hereditariedade do polimorfismo da ECA em ambos os casos.

- Você está sendo convidado a participar exatamente por fazer parte da comunidade acadêmica do UniCEUB

\section{Procedimentos do estudo}

- O procedimento consiste em coletar um total de três tubos de sangue (aproximadamente $15 \mathrm{~mL}$ ), dois tubos de EDTA, que serão destinados à extração do material genético e avaliação hematológica, e um tubo com gel, para os exames bioquímicos. A coleta será feita através da punção de uma veia superficial venosa na fossa antecubital do braço esquerdo ou direito.

- Não haverá nenhuma outra forma de envolvimento ou comprometimento neste estudo.

- Em caso de gravação, filmagem, fotos, explicitar a realização desses procedimentos.

- A pesquisa será realizada nos laboratórios do LaboCien (UniCEUB);

- Todos os procedimentos serão realizados por pessoas treinadas e sob supervisão de um profissional.

\section{Riscos e benefícios}

- Este estudo possui risco de desconforto e/ou mal-estar, que são pertinentes do procedimento de coleta

- Medidas preventivas durante a coleta de sangue serão tomadas para 
minimizar qualquer risco ou incômodo.

- Caso esse procedimento possa gerar algum tipo de constrangimento você não precisa realizá-lo.

- Sua participação poderá ajudar no maior conhecimento sobre a frequência dos genes relacionados a ECA e a sua relação com casos de hipertensão.

\section{Participação, recusa e direito de se retirar do estudo}

- Sua participação é voluntária. Você não terá nenhum prejuízo se não quiser participar.

- Você poderá se retirar desta pesquisa a qualquer momento, bastando para isso entrar em contato com um dos pesquisadores responsáveis.

- Conforme previsto pelas normas brasileiras de pesquisa com a participação de seres humanos você não receberá nenhum tipo de compensação financeira pela sua participação neste estudo.

\section{Confidencialidade}

- Seus dados serão manuseados somente pelos pesquisadores e não será permitido o acesso a outras pessoas.

- O material com as suas informações (fitas, entrevistas etc.) ficará guardado sob a responsabilidade do (a) pesquisador Paulo Roberto Queiroz, garantida a manutenção do sigilo e confidencialidade. Os dados e instrumentos utilizados ficarão arquivados com o (a) pesquisador (a) responsável por um período de 5 anos, e após esse tempo serão destruídos.

- Os resultados deste trabalho poderão ser apresentados em encontros ou revistas científicas, entretanto, ele mostrará apenas os resultados obtidos como um todo, sem revelar seu nome, instituição a qual pertence ou qualquer informação que esteja relacionada com sua privacidade.

Se houver alguma consideração ou dúvida referente aos aspectos éticos da pesquisa, entre em contato com o Comitê de Ética em Pesquisa do Centro Universitário de Brasília - CEP/UniCEUB, que aprovou esta pesquisa, pelo telefone 3966.1511 ou pelo e-mail cep.uniceub@uniceub.br. Também entre em contato para informar ocorrências irregulares ou danosas durante a sua participação no estudo.

$\mathrm{Eu}$,

RG após receber uma explicação completa dos objetivos do estudo e dos procedimentos envolvidos concordo voluntariamente em fazer parte deste estudo.

Este Termo de Consentimento encontra-se impresso em duas vias, sendo que uma cópia será arquivada pelo pesquisador responsável, e a outra será fornecida ao senhor (a).

Brasília, de de 
Nathalia Oliveira,nath.o.b.s@gmail.com

\section{Endereço dos (as) responsável (eis) pela pesquisa (OBRIGATÓRIO):}

Instituição: Centro Universitário de Brasília- UniCeub

Endereço: SEPN 707/907

Bloco: $\quad N^{\circ}$ : $\quad$ Complemento:

Bairro: Asa Norte CEP: 70790-075 Cidade: Brasília- DF

Telefones p/contato: (61) 3966-1200

Telefone:

Email:

Acrescente ao TCLE de sua pesquisa as informações abaixo caso sejam necessárias.

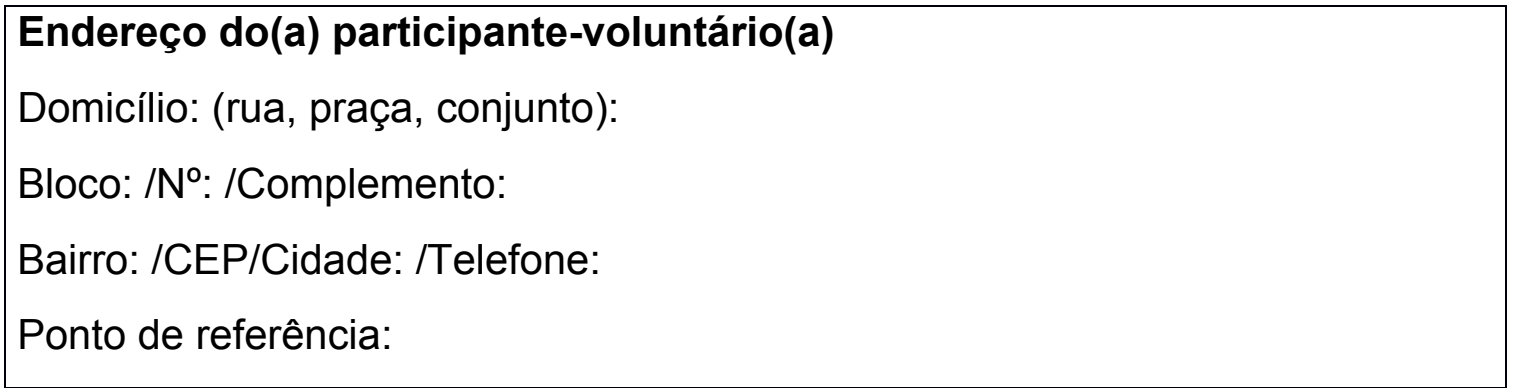

Nas pesquisas com metodologias experimentais na área biomédica, envolvendo seres humanos, incluir:

a) explicitar, quando pertinente, os métodos terapêuticos alternativos existentes;

b) esclarecer, quando pertinente, sobre a possibilidade de inclusão do participante em grupo controle ou placebo, explicitando, claramente, o significado dessa possibilidade; e

c) não exigir do participante da pesquisa, sob qualquer argumento, renúncia ao direito à indenização por dano. O Termo de Consentimento Livre e Esclarecido não deve conter ressalva que afaste essa responsabilidade ou que implique ao participante da pesquisa abrir mão de seus direitos, incluindo o direito de procurar obter indenização por danos eventuais.

Contato de urgência: $\mathrm{Sr}(\mathrm{a})$.

Domicílio: (rua, praça, conjunto)

Bloco: / $N^{\circ}$ : /Complemento: 


\subsection{Anexo D- Questionário para análise da qualidade de vida}

Idade:

Sexo:

Peso:

Altura:

1. Em sua família existem casos de hipertensão?

( ) Sim ( ) Não

2. Com que frequência você pratica atividade física?

( ) Raramente

( ) Uma vez por semana

( ) Duas vezes por semana

( ) três vezes por semana

( ) Mais de três vezes por semana

\section{Com relação aos hábitos alimentares, você:}

( ) Costumo me alimentar de comidas do tipo fast food (exemplo: batatas fritas e hambúrguer)

( ) Dou preferência a frutas e verduras

( ) Geralmente acrescento sal ou outros molhos industriais em minhas refeições

( ) Costumo comer salada com regularidade

( ) Consumo alimentos em conserva (exemplo: seleta de legumes, azeitonas e milho)

4. Com relação a ingestão de bebida alcoólica:

( ) Não ingiro bebida alcoólica

( ) Consumo ao menos uma vez por dia

( ) Consumo ao menos duas vezes por semana

( ) Consumo ao menos três vezes por semana

( ) Consumo mais de três vezes por semana

5. Com que frequência você ingere água?

( ) Costumo beber $200 \mathrm{ml}$ de água por dia (1 copo americano)

( ) Costumo beber $400 \mathrm{ml}$ de água por dia (2 copos americanos)

( ) Costumo beber $800 \mathrm{ml}$ de água por dia (4 copos americanos)

( ) Costumo beber 1,6L de água por dia (8 copos americanos)

( ) Costumo beber mais de 1,6L de água por dia 